TITLE:

\title{
Spatial and Temporal Distribution of Echinoderms in Rocky Nearshore Areas of Alaska
}

\section{$\operatorname{AUTHOR}(\mathrm{S})$ :}

CHENELOT, HELOISE; IKEN, KATRIN; KONAR, BRENDA; EDWARDS, MATTHEW

\section{CITATION:}

CHENELOT, HELOISE ... [et al]. Spatial and Temporal Distribution of Echinoderms in Rocky Nearshore Areas of Alaska. Publications of the Seto Marine Biological Laboratory. Special Publication Series 2007, 8: 11-28

\section{ISSUE DATE:}

2007

URL:

http://hdl.handle.net/2433/70914

RIGHT: 


\title{
Spatial and Temporal Distribution of Echinoderms in Rocky Nearshore Areas of Alaska
}

\author{
Héloïse Chenelot ${ }^{1 *}$, Katrin Iken ${ }^{1}$, Brenda Konar $^{1}$ and Matthew Edwards ${ }^{2}$ \\ '245 O’Neill Bldg, School of Fisheries and Ocean Sciences, University of Alaska, \\ Fairbanks, Fairbanks, Alaska 99775, USA \\ ${ }^{2}$ Department of Biology, San Diego State University, San Diego, CA 92182, USA \\ Corresponding author's e-mail: heloisec@ims.uaf.edu
}

\begin{abstract}
Among near shore invertebrates, echinoderms play an important role in the structure (specifically in food web structure) and function of rocky intertidal and shallow subtidal communities because of their high densities, biomass, and versatile ecological functions. Alaska has a variety of near shore echinoderm species, but little is known about their spatial and temporal distribution. Rocky habitats were surveyed following Natural Geography in Shore Areas (NaGISA) protocols in three areas of the Gulf of Alaska (Prince William Sound, Kachemak Bay, and Kodiak Island) in 2003 and 2004. Within each area, two to three sites were destructively sampled. The abundance of echinoderms within five $25 \times 25 \mathrm{~cm}$ quadrats was recorded in the high, mid, and low intertidal heights and $1 \mathrm{~m}, 5 \mathrm{~m}$, and $10 \mathrm{~m}$ depths. We attempted to detect interannual variability in the distribution of echinoderms and to evaluate whether distribution was different along horizontal scales between regions 100's of kilometers apart and, within each region, between sites 10's of kilometers apart. We also looked at tidal height as a factor of variation and tried to determine if any vertical patterns were consistently observed over time and over regional and local areas. The diversity and abundance of echinoderms were greatly variable between our two sampling events and over all spatial scales. No clear patterns were identified over time and over (regional and local) horizontal gradients. However, different echinoderm groups showed distinctive distribution patterns over the vertical immersion gradient, with asteroids and holothuroids being more abundant in the intertidal and shallow subtidal zone and ophiuroids being more abundant at deeper depths.
\end{abstract}

Key words: Echinoderm distribution, asteroids, ophiuroids, holothuriods, temporal variability, horizontal variability, vertical variability, Prince William Sound, Kachemak Bay, Kodiak Island

\section{Introduction}

Echinoderms are an entirely marine phylum whose populations are prevalent in benthic ecosystems throughout the world's oceans. They are often the largest and most conspicuous organisms on both sandy and rocky substrates in polar (Piepenburg et al., 1997; Feder et al., 2005) and temperate (Paine, 1966; Menge et al., 1994) littoral zones, as well as in the deep sea (Billett, 1991; Billett et al., 2001; Howell et al., 2002). As a consequence of their high abundance and biomass, along with the diversity of their feeding types, they can be important in energy transfer among trophic levels within coastal communities (Ambrose et al., 2001). Consequently, echinoderms often play a determinant role in structuring nearshore ecosystems, and in extreme cases can lead to the formation of 'alternate stable states', such as urchin barrens vs. kelp forests (Mann and Breen, 1972; Duggins, 1980; Estes et al., 1998; Konar and Estes, 2003) or diverse intertidal communities vs. mussel beds (Paine, 1966). Therefore, understanding how these organisms are distributed in space and time can lead to increased understanding of structure and functioning of coastal ecosystems.

While large-scale patterns of distribution and abundance are known for some echinoderm taxa in certain regions (Piepenburg, 2000; Ellingsen and Gray, 2002), most of this information is available 
only for subtidal habitats where spatial and temporal variability appear relatively low (Migne and Davoult, 1997; Hinz et al., 2004), though local migration of some species may periodically increase this variability (Gonzales-Medina et al., 2006). In contrast, spatial variability in echinoderm abundance in intertidal systems can be relatively high, with a substantial amount of variation observed at very small (meters) spatial scales, especially when compared with much larger (100's of kilometers) spatial scales (Menconi et al., 1999; Benedetti-Cecchi, 2001; Chapman, 2002, 2005). How patterns of spatial variability along vertical gradients compare between intertidal and subtidal habitats or among geographic areas, however, remains poorly understood and is the focus of this study.

As with many other organisms, echinoderms are patchily distributed in space and time (Gutt and Starmans, 2003). Much of the spatial and temporal variability in their abundance may result from the inherent patchiness in the more complex communities to which they belong (Connell, 1972; Pickett and White, 1985). The causes of this patchiness can be numerous and include variation in the physical environment, recruitment dynamics, food supply, predation, or simply be due to the gregarious behavior of certain taxa (Connell, 1972; Duggins, 1983; Burke, 1986; Vadas et al., 1986; Raimondi, 1990; Carroll and Highsmith, 1996; Noda, 1999; Hunt and Schiebling, 2001). All of these factors may be strongly scale-dependent. In fact, regardless of the particular reason(s), numerous discussions on the issue warn that there is no single scale at which such patters can be adequately studied, but instead recommend they be studied at numerous scales simultaneously (Dayton and Tegner, 1984; Weins, 1989; Levin, 1992, 2000; Edwards, 2004). While a full understanding of the temporal scales of variability may require long-term monitoring efforts, spatial scales of variability can easily be assessed using the appropriate sampling designs. For example, hierarchical (fully-nested) sampling protocols may be particularly useful for studying both local and broad-scale patterns of organism abundance (Hughes et al., 1999; Edwards, 2004). Such designs provide the added benefit in that they facilitate analytical techniques that partition variability among different levels of the hierarchy (Underwood, 1997; Graham and Edwards, 2001), thus providing insight into the relative importance of processes acting at each scale. For instance, consistency in organism abundance (i.e. low spatial variance) observed at one spatial scale might indicate that consistent distribution patterns may override any inherent patchiness at that scale. In contrast, a lack of consistency in abundance (i.e. high spatial variance) observed at a particular scale might indicate that inherent patchiness may outweigh factors that result in consistency. To better understand the nature of this spatial and temporal variability, to discern the scales at which patchiness most strongly occurs, and to assess how general vertical zonation patterns are, we studied patterns of echinoderm abundance along the vertical tidal gradient at numerous sites from three geographic regions throughout the Gulf of Alaska over a two-year period.

The Natural Geography in Shore Areas (NaGISA) Project within the Census of Marine Life (CoML) Program is devoted to assessing patterns of biodiversity in nearshore communities at multiple temporal and spatial scales throughout the world's oceans (web site located at: http://www.coml.nagisa.org). In the Northeast Pacific, this sampling program has produced a comprehensive data set that has allowed us to analyze patterns of echinoderm abundance in intertidal and shallow subtidal habitats with the ultimate goal of discerning the underlying patterns of distribution and abundance. In this study, we describe patterns of spatial variation in echinoderm abundance along a horizontal emersion/depth gradient extending from the high intertidal to $10 \mathrm{~m}$ subtidal depth in the Gulf of Alaska over a two-year period. The sampling protocols allow us to partition patterns of variability among three spatial scales (within-site = meters apart, among-sites = 10 's of kilometers apart, and among-regions $=100$ 's of kilometers apart), six vertical heights (high, middle and low intertidal, $1 \mathrm{~m}, 5 \mathrm{~m}$ and $10 \mathrm{~m}$ subtidal depth), and between two sample years (2003, 2004). Our specific objectives were to answer the following questions:

1) Did echinoderm diversity and abundance vary between 2003 and 2004? 
2) Does echinoderm diversity and abundance vary between the three distinct geographic regions (separated by 100's of kilometers)?

3) Does echinoderm diversity and abundance vary between sites within each region (separated by 10 's of kilometers)?

4) Does echinoderm diversity and abundance vary over a vertical gradient, from the high intertidal to $10 \mathrm{~m}$ in depth?

5) Do these vertical patterns vary over time, among regions, or among sites within regions and are they specific to different echinoderm groups?

6) When all factors are examined simultaneously, how much does each contribute to the overall amount of variability in echinoderm abundance?

\section{Methods}

\section{Study sites}

This study occurred in late May to June of 2003, and June to early July of 2004 in three distinct

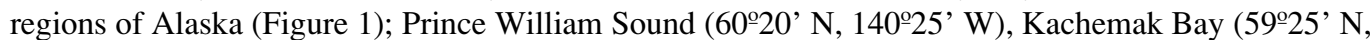

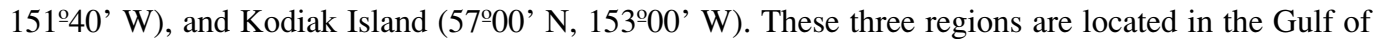
Alaska and are separated from one another by 100's of kilometers. Within each region, two or three sites separated from one another by 10's of kilometers and dominated by macroalgae were chosen based on similar hydrography, substrate type (rocky) and wave exposure. In Prince William Sound, the three sites were located in the southern part of the sound and were Knight Island (KI), Montague Island (MI), and Green Island (GI). In Kachemak Bay, the two sites were located on the south shore of the bay and were Cohen Island $(\mathrm{CI})$, and Outside Beach (OB). At Kodiak Island, the two sites on the

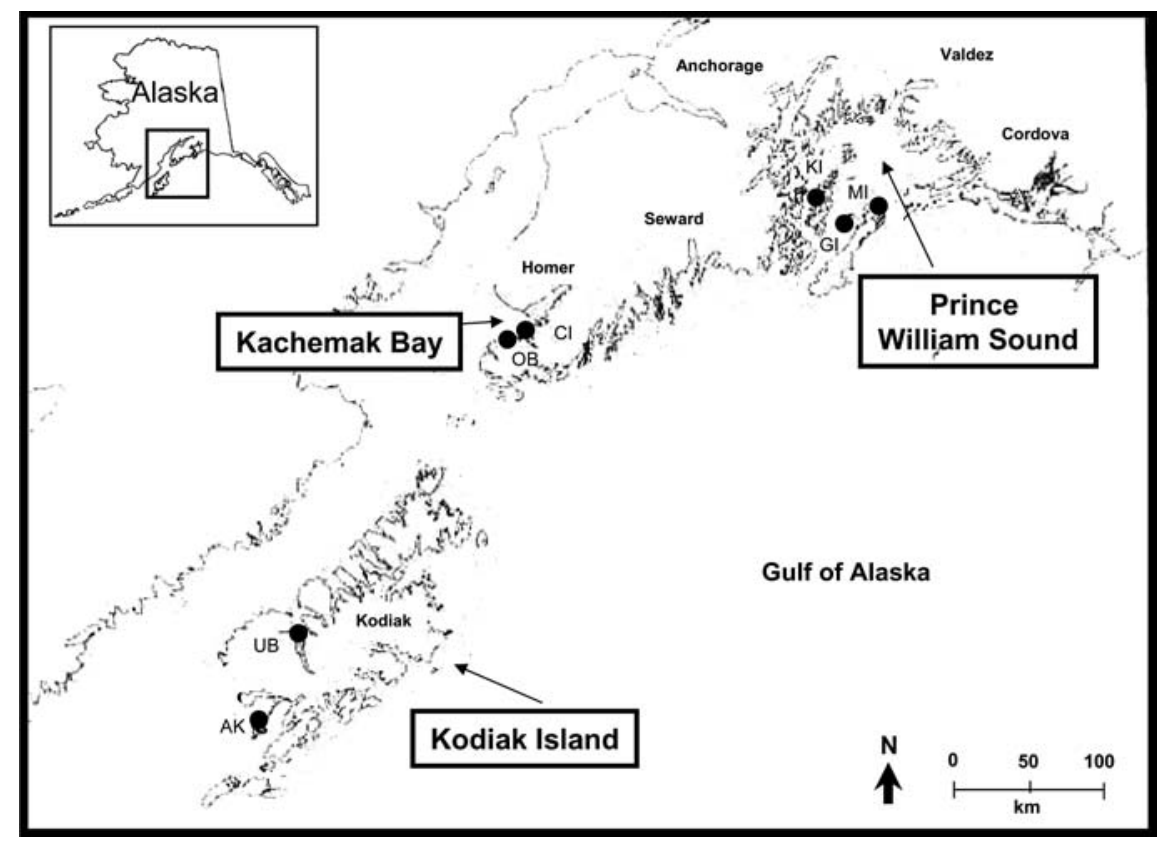

Fig. 1. Map of the study sites in the Gulf of Alaska. Hard-bottom nearshore sites were sampled within three distinct regions in 2003 and 2004. Knight Island (KI), Montague Island (MI), and Green Island (GI) were sampled in Prince William Sound. Cohen Island (CI) and Outside Beach (OB) were sampled in Kachemak Bay. Alitak Bay (AK) and Uyak Bay (UB) were sampled around Kodiak Island. 
western side of the island were Alitak Bay (AK), and Uyak Bay (UB).

\section{Sample collection}

All samples were collected following the NaGISA protocols (Nakashizuka and Stork, 2002; see Rigby et al., 2007 for fuller detail). Briefly, at each site, six tidal heights were sampled including the high, middle and low intertidal, and $1 \mathrm{~m}, 5 \mathrm{~m}$ and $10 \mathrm{~m}$ subtidal depths. The $5 \mathrm{~m}$ and $10 \mathrm{~m}$ heights were sampled using SCUBA, while the rest were sampled at low tide. At each height, five replicate $25 \times 25 \mathrm{~cm}$ quadrats were placed at randomly chosen distances along a $30 \mathrm{~m}$ transect that was laid parallel to the shoreline. All organisms were removed from each quadrat, placed into 500 $\mu \mathrm{m}$ mesh bags, and preserved in $10 \%$ buffered formaldehyde. Samples were brought to the laboratory where all the echinoderms were removed, counted, and identified to the lowest taxonomic level possible. Because of taxonomic uncertainties regarding species within the genera Amphipholis, Henricia, Leptasterias, and Solaster, questionable specimens were grouped at the genus level. A few specimens could only be identified to the family level, while several small juveniles were only identified to the class level. Large, conspicuous echinoderms were not brought to the lab but were identified and measured in the field.

\section{Data analyses}

Biodiversity indices, species richness (S) and the Shannon-Weiner Diversity Index (H', log base e), were calculated using Primer statistical software (PRIMER vs 6, Primer-E, Ltd., 2001). All diversity and abundance values were $\log (\mathrm{x}+1)$ transformed prior to testing to satisfy assumptions of normality and equal variances. Separate statistical analyses were performed for each biodiversity index and each class of echinoderms. Four-way nested ANOVA's with Sample 'Year', Tidal 'Height' and Geographic 'Region' as fixed factors, and Study 'Sites' nested within 'Regions' as a random factor were performed to assess 1) temporal variation in abundance/diversity between the two sampling events (2003 and 2004), 2) spatial variation in abundance/diversity between regions and sites within regions, and 3) variability in abundance/diversity among tidal heights (SYSTAT, v 10.0). While we recognize that 'Year' and 'Region' may also be considered as random factors, our decision to consider them as fixed factors was based on the inability to test the main effect of 'Height' (one of the most important factors in the model) when either of these was considered random. This occurred because the numerous interactions in the full ANOVA model prevented us from identifying the correct mean square denominator in our F-tests. Traditional methods of removing problematic interaction terms such as post-hoc pooling were not possible because many of the interactions were significant (Underwood, 1997). We present summary results for the analyses but full ANOVA tables for all analyses can be requested from the authors. Because 'Regions' showed significant interactions with the other factors in nearly all the ANOVAs (see Results), we further examined patterns of echinoderm abundance and diversity among 'Heights', 'Years' and 'Sites' within each region separately using three-way mixedmodel ANOVAs; for consistency, we assigned factors as fixed or random as described above.

Multidimensional scaling (MDS) analyses were used to plot community similarity patterns based on abundance of echinoderm taxa from samples at all sites and all tidal heights within Prince William Sound, Kachemak Bay, and Kodiak Island in 2003 and 2004 (PRIMER vs 6, Primer-E, Ltd., 2001). The data were $\log (x+1)$ transformed and the Bray-Curtis coefficient was used as a resemblance parameter. The multivariate patterns in terms of region, site or depth stratum resemblances were depicted in separate ordination plots.

\section{Results}

\section{Echinoderm diversity and abundance}

A total of 24 unique taxa from four classes were recorded (Table 1) during this study, including 
ECHINODERm Distribution in the Rocky NeARshore, Alaska

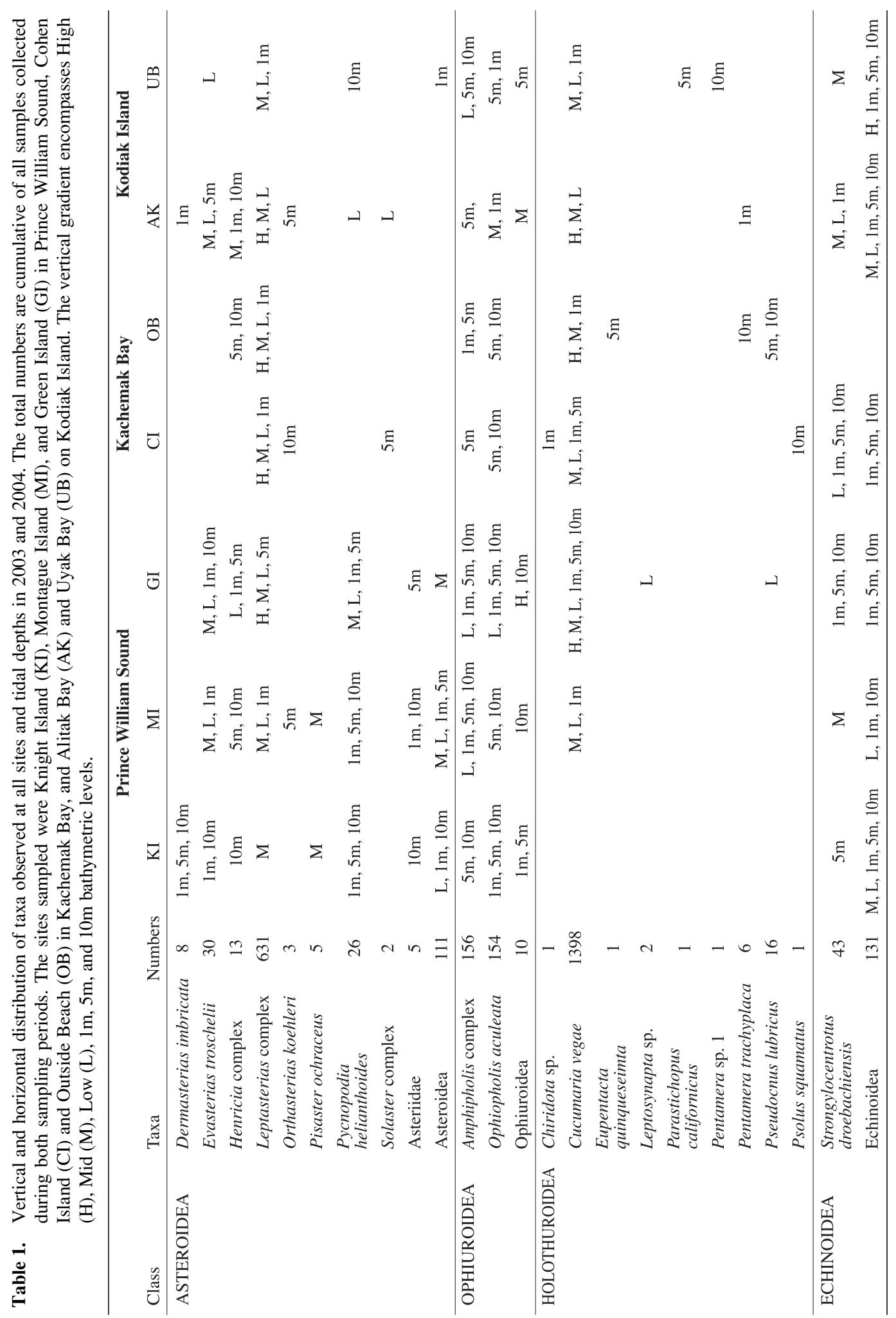


ten asteroids, nine holothuroids, three ophiuroids, and two echinoids. The most abundant echinoderms were the holoturoid Cucumaria vegae and the asteroid Leptasterias spp. complex. Some taxa, such as Leptasterias spp Ophiopholis aculeata, C. vegae, and Strongylocentrotus droebachiensis, were found in many samples in all regions. In contrast, some groups occurred with only one or two specimens, including Pisaster ochraceus, Chiridota sp., Eupentacta quinquesemita, Leptosynapta sp., Parastichopus californicus, Pentamera sp., and Psolus squamatus. Spatial variation in species composition also was seen across vertical gradients. While some taxa were observed at most tidal heights, such as Evasterias troschelii, Pycnopodia helianthoides, and S. droebachiensis, others were restricted to specific immersion levels in the intertidal (such as Leptasterias spp.) or the subtidal (such as Amphipholis spp. and O. aculeata) zones (Table 1).

\section{Temporal variation in echinoderm diversity and abundance}

No clear effects or patterns of interannual variability on echinoderm diversity and abundance were observed among the different regions, sites, and echinoderm groups. The effect of years was inconsistent between regions for all variables $\left(p<0.05\right.$ for all 'Year*Region' interactions, although $\omega^{2}$ varied from 0.000 for H' to 0.171 for Asteroids; Table 2). Both biodiversity indices tended to increase from 2003 to 2004 in Prince William Sound but decreased at Kodiak, while they decreased at only one (CI) of the 2 sites in Kachemak Bay (Table 2; Figure 2). Patterns in echinoderm abundance also were inconsistent between the 2 sampling events and varied at the regional scale, with the overall echinoderm abundance remaining similar in Prince William Sound and at Kodiak but decreasing in Kachemak Bay (Table 2; Figure 3). In addition, within each region, the interannual variability diverged from site to site and strongly depended on which echinoderm group was examined (Table 3; Figure 3). For example, from 2003 to 2004, asteroid abundance in Kachemak Bay significantly decreased at CI but only to a lesser extent at OB $\left(p=0.003, \omega^{2}=0.205\right)$, while holothuroid abundance increased in AK but decreased in UB around Kodiak Island during that period $\left(p=0.041, \omega^{2}=0.062\right)$. The biodiversity and abundance of echinoderms along the tidal gradient were not significantly different between the 2 sampling years ( $p>0.05$ for most 'Year*Height' interactions; Table 2 and 3; Figure 4 and 5).

\section{Horizontal spatial variation in echinoderm diversity and abundance}

Although the regional effect was not significant $(p>0.05)$ and only contributed to a small portion of the variability of echinoderm diversity and abundance (most $\omega^{2}<0.05$ ), 'Region' strongly interacted with other factors (as shown by $p<0.05$ for numerous interaction terms; Table 2). Those overwhelming, significant interactions suggested that echinoderm diversity and abundance patterns with years and tidal heights significantly changed from one region to the other (Figure 2 and 3). As a result, the experimental variables (biodiversity indices, $\mathrm{S}$ and H', and abundance of asteroids, ophiuroids, holothuroids, and echinoids) were further examined within each region separately.

Significant local variations in echinoderm diversity and abundance were found between sites within each region but no consistent patterns were observed between regions or among the variables examined (Table 3; Figure 2 and 3). Echinoderm diversity indices (S and H') significantly differed along the tidal gradient between the 3 Prince William Sound's sites $\left(p=0.001\right.$ and $0.011, \omega^{2}=0.115$ and 0.338 for $S$ and H', respectively). In Kachemak Bay, both biodiversity indices were dissimilar between sites, with the difference in the Shannon Diversity Index (H') being also affected by 'year' ( $p$ $=0.000$ and $0.032, \omega^{2}=0.553$ and 0.301 for $\mathrm{S}$ and $\mathrm{H}^{\prime}$, respectively). In contrast, echinoderm diversity was similar at both Kodiak sites $\left(p=0.475\right.$ and $0.196, \omega^{2}=0.001$ and 0.058 for $\mathrm{S}$ and $\mathrm{H}^{\prime}$, respectively; Table 3; Figure 2). In addition, echinoderm abundance was significantly different between sites within each region. All echinoderm groups within all 3 regions (except ophiuroids and echinoids in Kachemak Bay) were significantly affected by the interaction 'Height*Site' $(p<0.05$ and $\omega^{2}>0.110$; Table 3; Figure 3). Asteroids were present at all sites within all regions but in 


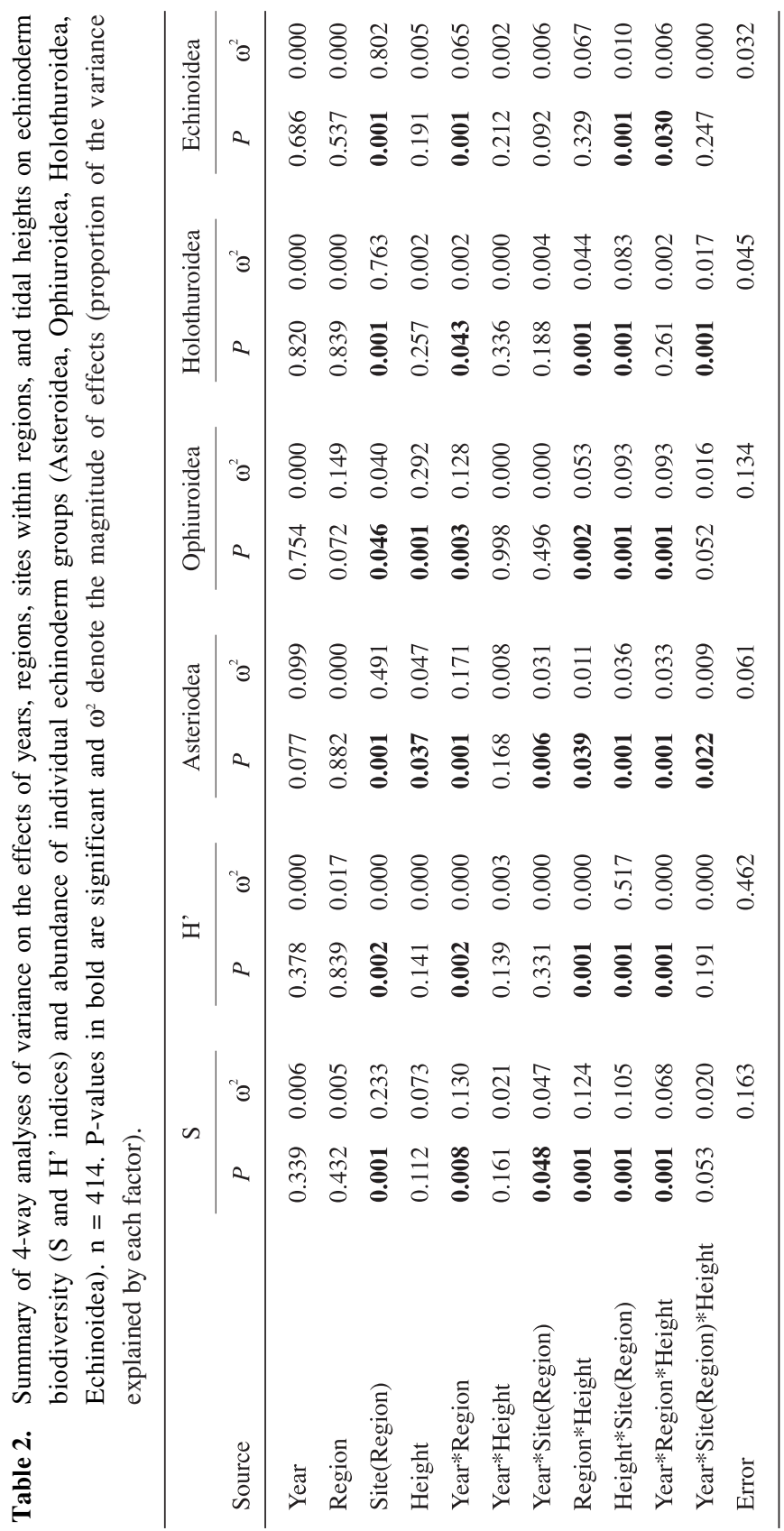


dramatically higher numbers at Cohen Island in 2003 (13.6 \pm 5.0 individuals / $625 \mathrm{~cm}^{2}$; mean \pm 1 SE) than at any other sites. Asteroid abundance at that site significantly decreased between 2003 and 2004 ( $p=0.003$ and $\omega^{2}=0.205$ for 'Site*Year'; Table 3; Figure 3a). Ophiuroids were present at all sites but significantly differed in numbers within each region $\left(p<0.05\right.$ and $\omega^{2}>0.110$ for 'Site' or 'Height*Site' within each region; Table 3; Figure 3b). In Prince William Sound, holothuroids were not found at $\mathrm{KI}$ in 2003 or in 2004 but were present in large numbers (13.7 \pm 5.9 individuals $/ 625 \mathrm{~cm}^{2}$; mean \pm 1 SE in 2004) at MI $\left(p=0.000\right.$ and $\omega^{2}=0.611$ for 'Site'; Table 3; Figure 3c). In both Kachemak Bay and Kodiak, holothuroid abundance was also affected by 'Site' and its interactions $(p<$ 0.05 and $\omega^{2}>0.112$; Table 3; Figure 3c). The number of echinoids observed was significantly variable among sites $\left(p<0.05\right.$ and $\omega^{2}>0.176$; Table 3$)$ and no echinoids were counted at $\mathrm{OB}$ in 2003 or in 2004 (Figure 3d).
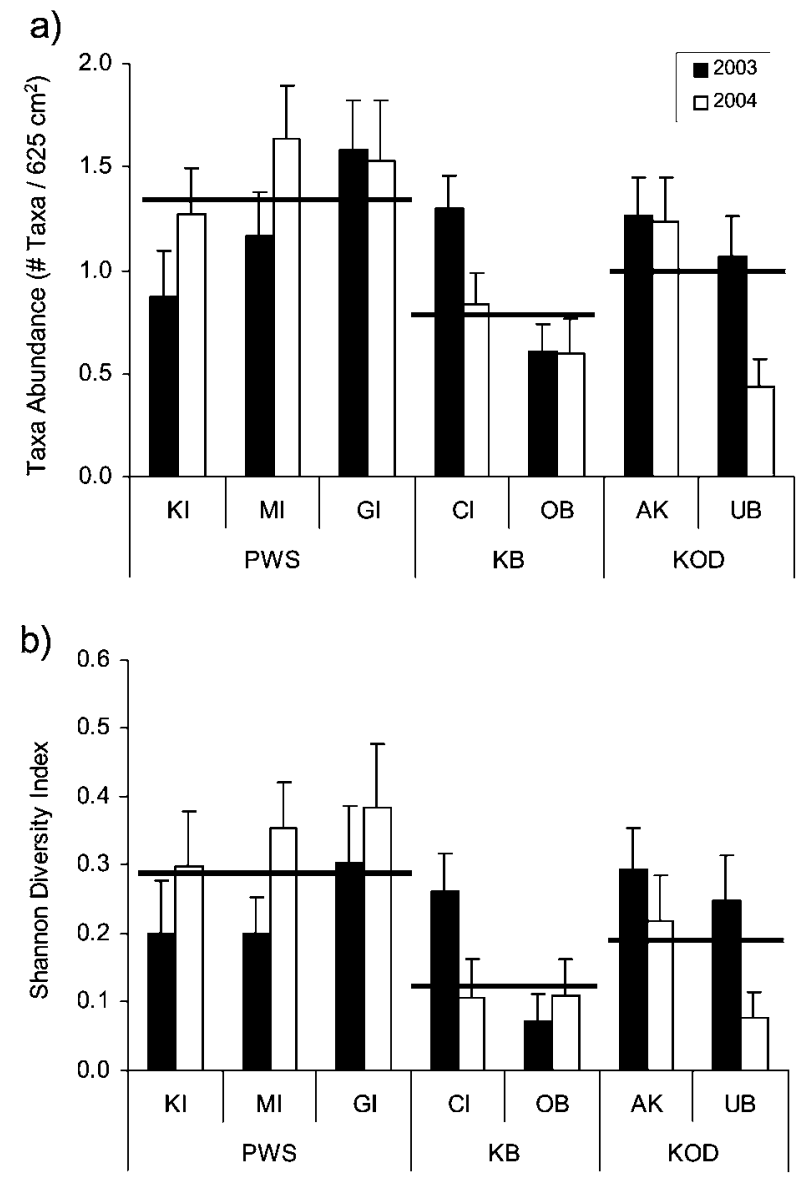

Fig. 2. Biodiversity indices, a) Taxa Abundance (S) and b) Shannon Divesity Index (H'), for echinoderms at each site in 2003 (black) and 2004 (white). The values represent the means $(+1$ $\mathrm{SE})$ of replicates from all tidal heights at each site. A horizontal black line marks the mean values for each region. The mean $\mathrm{S}$ values are 1.342 for Prince William Sound, 0.835 for Kachemak Bay, 0.998 for Kodiak. The mean H' values are 0.291 for Prince William Sound, 0.137 for Kachemak Bay, 0.209 for Kodiak. 


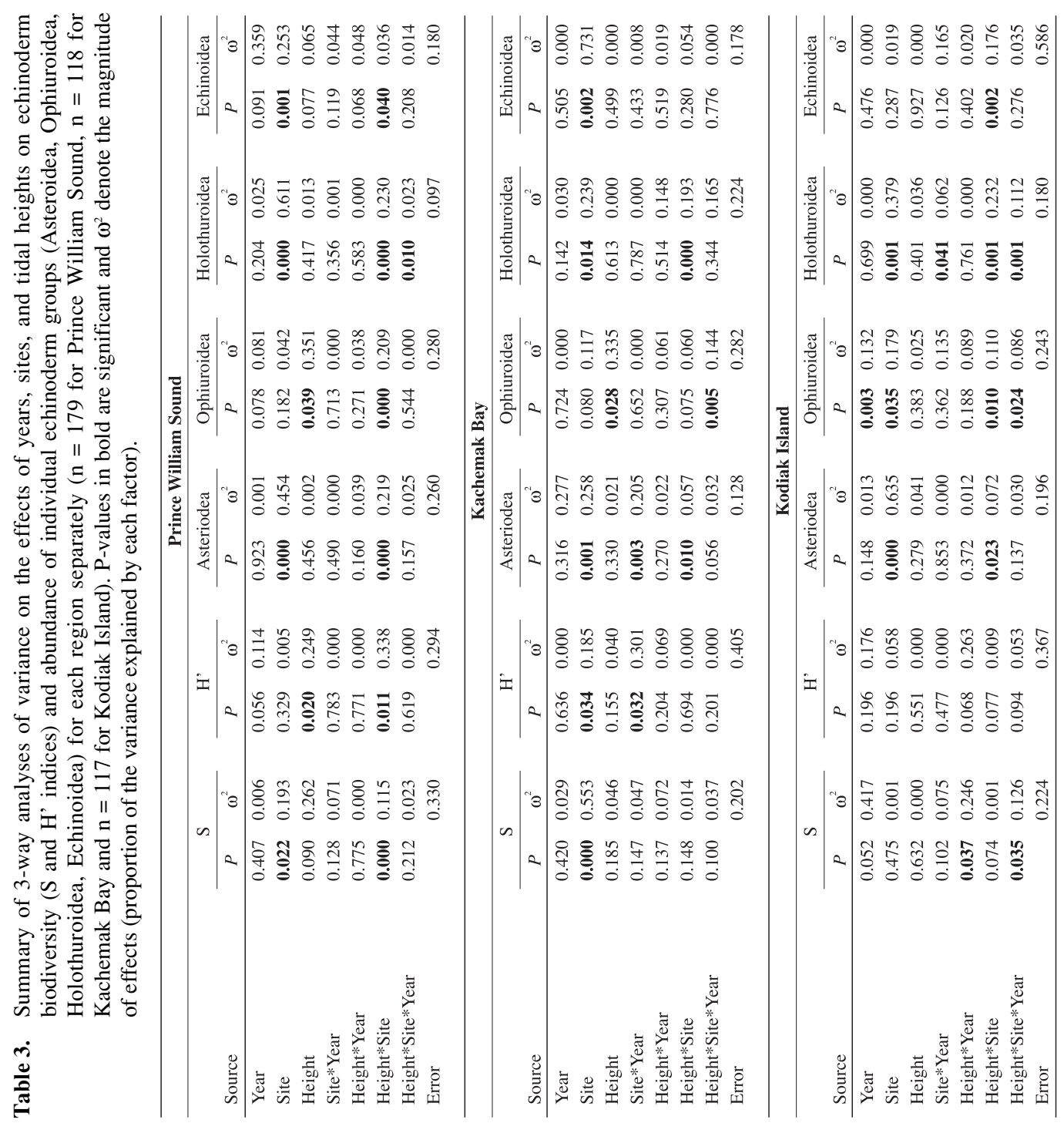




\section{Vertical spatial variation in echinoderm diversity and abundance}

Vertical gradient contributed to the amount of variation observed in echinoderm diversity and abundance but the patterns often varied from site to site and strongly depended on the echinoderm group being examined (Table 3; Figure 4 and 5). A general pattern seemed to show echinoderm biodiversity being lowest at the high tide level and peaking at the intertidal/subtidal transition zone (Figure 4). However, that trend was somewhat inconstant between sites in Prince William Sound ( $p=$ 0.000 and 0.011 , and $\omega^{2}=0.115$ and 0.338 for 'Height*Site' for $\mathrm{S}$ and H', respectively) and between years in Kodiak $\left(p=0.037\right.$ and 0.068 , and $\omega^{2}=0.246$ and 0.263 for 'Height*Year' for S and H', respectively; Table 3). Biodiversity indices for Kachemak Bay were not significantly influenced by tidal height ( $p=0.185$ and 0.155 , and $\omega^{2}=0.046$ and 0.040 for S and H', respectively; Table 3).

Echinoderm abundance for all groups showed much variation along the vertical gradient in all regions and sites (except for echinoids in Kachemak Bay). The effect of tidal height on the abundance of echinoderms was overall similar between years but often varied from site to site within regions (within all regions $p<0.05$ and $\omega^{2}>0.05$ for 'Height*Site' for most echinoderm groups; Table 3; Figure 5). In addition, the location of the echinoderms along the vertical gradient strongly varied for different echinoderm groups. In general, Asteroidea (Leptasterias spp.; Figure 5a) and Holothuroidea (Cucumaria vegae; Figure 5c) were found primarily in the intertidal area whereas Ophiuroidea (Amphipholis spp. and Ophiopholis aculeata; Figure 5b) were dominant in the subtidal area. Echinoids were found at most tidal heights, except high tide (Figure 5d). Within the Asteroidea, some individual taxa, such as Evasterias troschelii and Pycnopodia helianthoides were not restricted to any specific tidal height (Table 1).

a)

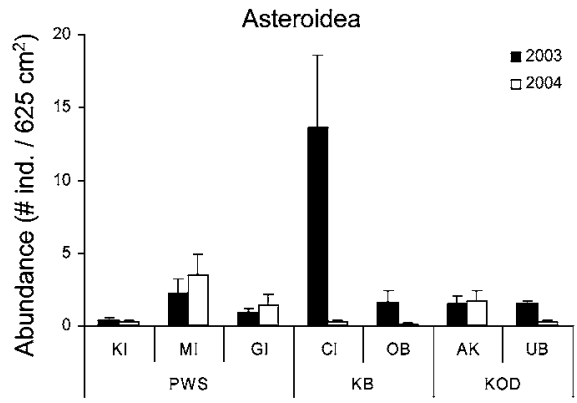

b)

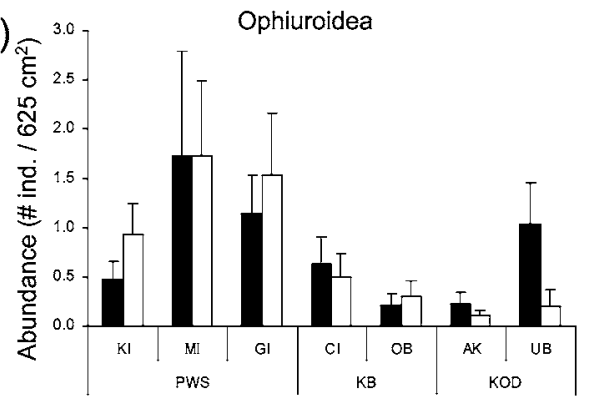

c)

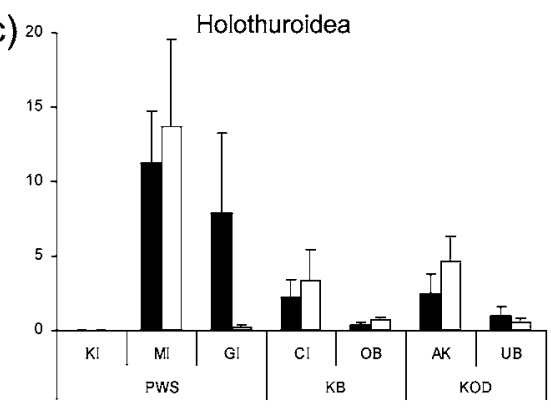

d)

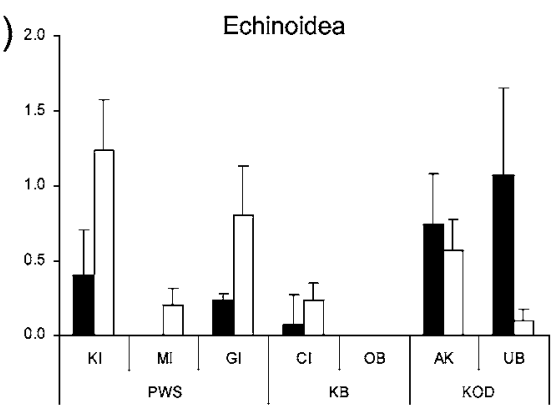

Fig. 3. Mean abundance of a) Asteroidea, b) Ophiuroidea, c) Holothuroidae, and d) Echinoidae at each site in 2003 (black) and 2004 (white). The values represent the means (+1 SE) of replicates from all tidal heights for each site. 


\section{Factors contributing to the overall variance in echinoderm diversity and abundance}

'Year', 'Region', 'Site (Region)', and tidal 'Height' were the factors used to try and explain the variations observed in echinoderm diversity and abundance (Table 2). Of those factors, 'Site (Region)' was the most important; it contributed to $23 \%, 49 \%, 76 \%$, and $80 \%$ of the total variation in species richness (S), and abundance of asteroids, holothuroids, and echinoids, respectively (Table 2). When looking at regions individually, 'Site' remained an important contributor to explaining variations in echinoderm diversity and abundance (Table 3). The variation in echinoderm diversity was explained by the combination of different factors in different regions; the variation in both biodiversity indices were mostly explained by 'Height' and 'Height*Site' in Prince William Sound, by 'Site' and 'Site*Year' in Kachemak Bay, and by 'Year' and 'Year*Height' in Kodiak (Table 3). The variations in asteroid and holothuroid abundance were mostly explained by 'Site' in all 3 regions $\left(\omega^{2}=0.454\right.$, 0.258 , and 0.635 for asteroids, and $\omega^{2}=0.611,0.239$, and 0.379 for holothuroids in Prince William Sound, Kachemak Bay, and Kodiak, respectively; Table 3). The factor 'Height' largely contributed to
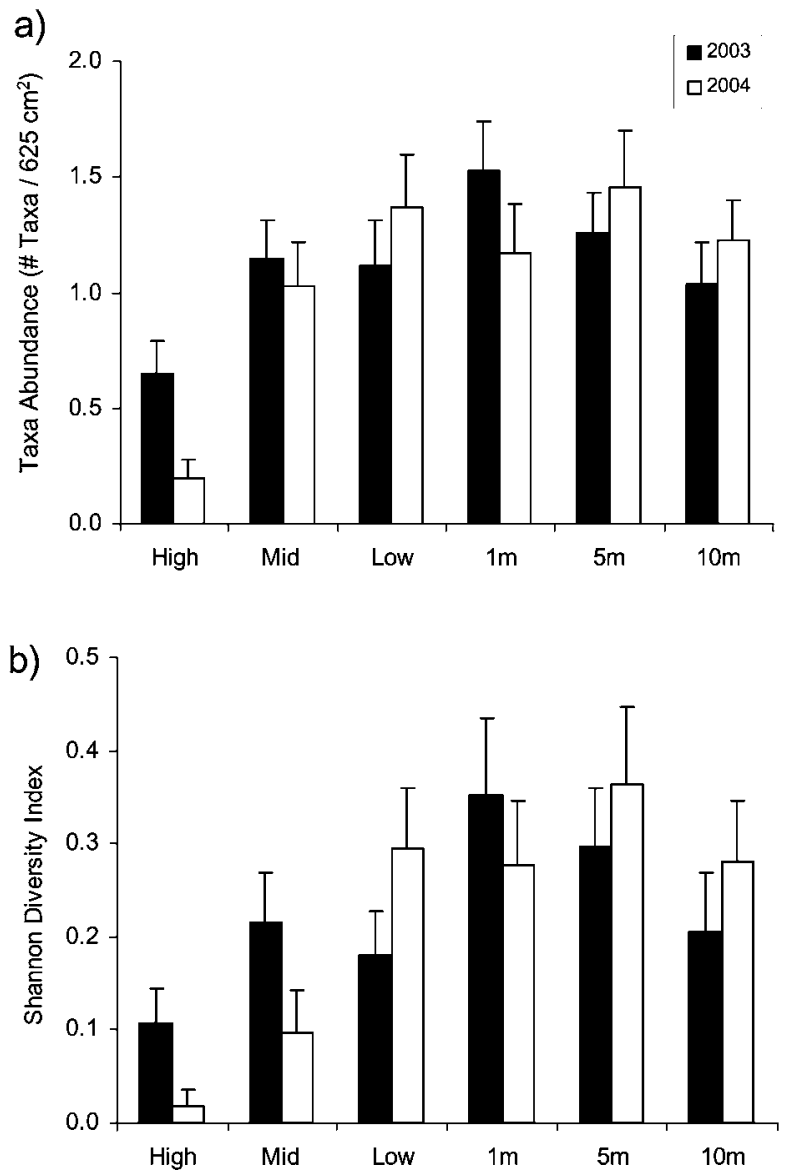

Fig. 4. Biodiversity indices, a) Taxa Abundance (S) and b) Shannon Divesity Index (H'), for echinoderms at each tidal height in 2003 (black) and 2004 (white). The values represent the means $(+1 \mathrm{SE})$ of replicates from all sites for each tidal height. 
a)

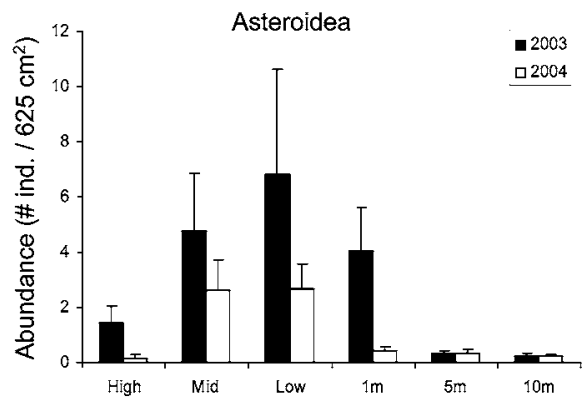

b)

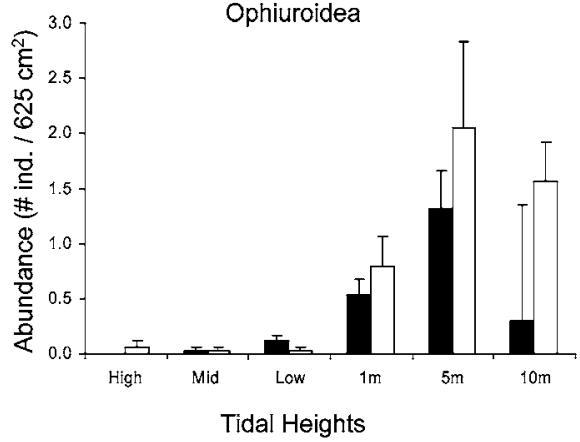

c)

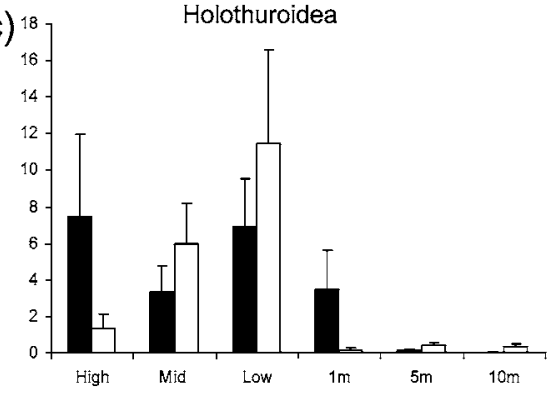

d)

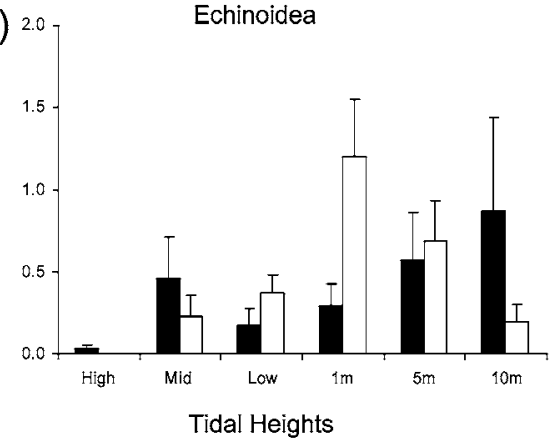

Fig. 5. Mean abundance of a) Asteroidea, b) Ophiuroidea, c) Holothuroidea, and d) Echinoidea at each tidal height in 2003 (black) and 2004 (white). The values represent the means (+1 SE) of replicates from all sites for each tidal height.

the variation in ophiuroid abundance in all 3 regions $\left(\omega^{2}=0.351,0.335\right.$, and 0.179 in Prince William Sound, Kachemak Bay, and Kodiak, respectively; Table 3), whereas the variation in echinoid abundance was due to different factors in different regions; it was explained at $36 \%$ by 'Year' in Prince William Sound, at $73 \%$ by 'Site' in Kachemak Bay, and at $16 \%$ and $18 \%$ by 'Site*Year' and 'Height*Site' in Kodiak (Table 3). Although the factors used in the models fit the data well $(r=0.495$ to 0.825 for all echinoids in Kachemak Bay and holothuroids in Prince William Sound, respectively; values not shown in tables), the error terms contributed in most cases to a relatively large portion of the variance in echinoderm diversity and abundance $\left(\omega_{\text {error }}^{2}=0.097\right.$ to 0.586 for Holothuroids in Prince William Sound and Echinoids in Kodiak, respectively; Table 3).

Overall echinoderm community structure, as displayed with MDS ordination plots based on abundance data, did not show marked differences by regions (Figure 6a) or by sites (Figure 6b), emphasizing the large variability on these scales as described above. However, echinoderm communities showed some consistent trends when scored by tidal zones. The community grouped clearly into the intertidal zone (including High, Mid, and Low strata) and subtidal zone (including $5 \mathrm{~m}$ and $10 \mathrm{~m}$ depths); the $1 \mathrm{~m}$ stratum was kept separate based on the large tidal range in south-central Alaska and grouped between intertidal and subtidal but more closely with the intertidal community (Figure 6c).

\section{Discussion}

This study suggests that echinoderm distribution (diversity and abundance) is highly variable over interannual and various spatial scales, and that patterns can be different for different echinoderm 

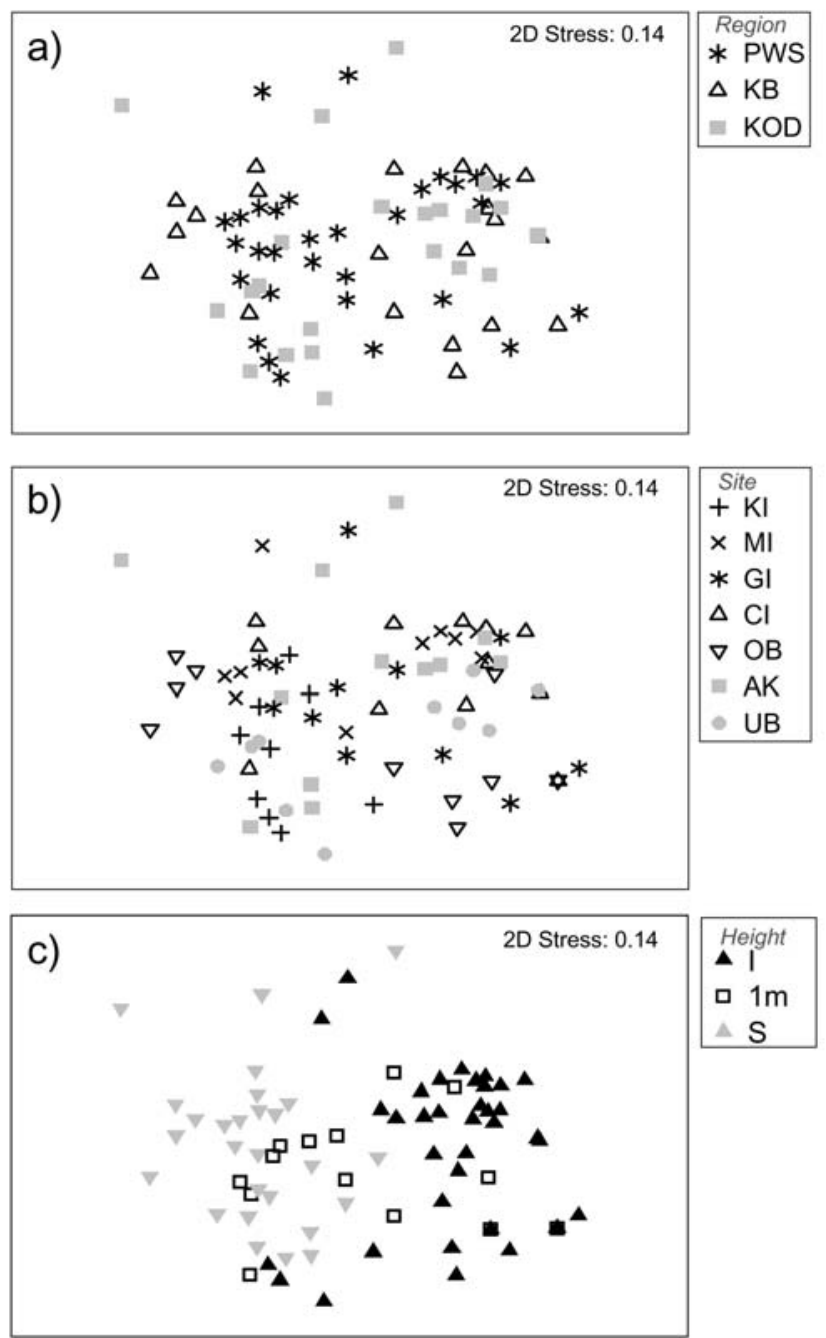

Fig. 6. MDS plot for abundance of echinoderm taxa based on samples at all sites and all tidal heights within Prince William Sound, Kachemak Bay, and Kodiak Island in 2003 and 2004. The data were $\log (x+1)$ transformed and resemblance was based on Bray-Curtis similarities (2D Stress $=0.14$ ). Community similarity patterns are plotted by a) Regions, b) Sites, and c) Tidal Heights (Intertidal, 1m, and Subtidal strata).

groups. This supports the general belief that nature is often unpredictable and consistent trends can be difficult to find. In this study, we found mostly inconsistent trends in echinoderm distribution patterns between the two sampling years, among regions or sites, and along the vertical immersion gradient. However, trends in vertical distribution across tidal heights seemed more reliable and distinct for individual echinoderm groups. This is not surprising as most species have numerous biological and physiological attributes that are defined along the tidal emersion gradient that limits their distribution.

In general, some interannual variation was found in overall echinoderm diversity and abundance but no consistent increase or decrease in the measured variables was observed between 2003 and 2004 . 
This suggests that interannual variation may be due to a combination of localized (small-scale) physical and/or biological factors that may affect specific echinoderm classes or species. Marine communities can change due to major shifts in environmental conditions, such as those triggered by El Niño (e.g. Tegner and Dayton, 1991; Dayton et al., 1998; Connolly and Roughgarden, 1999; Edwards, 2004, 2005; Paine and Trimble, 2004) or Pacific Decadal Oscillations (e.g. Smith et al., 2006; Springer, 1998). On a shorter scale, seasonal variations in marine communities have often been documented (Menconi et al., 1999; Hinz et al., 2004; Balata et al., 06). Temporal heterogeneity in marine systems also can occur due to more sporadic and localized events (McNaughton, 1977; Rumrill, 1989; Hastings et al., 1993; Hinz et al., 2004). It is likely that such temporal variation in environmental conditions may not affect all echinoderm groups equally. Groups may cope differently with fluctuations due to their physiological adaptations, or the degree of exposure based on their distribution pattern (e.g., intertidal taxa may be exposed to more drastic temperature differences than subtidal taxa), as seen in many invertebrates (Aarset, 1982; Loomis, 1995; Davenport and MacAlister, 1996).

Echinoderm diversity and abundance were affected by horizontal regional gradients but the responses were sometimes inconsistent between years and were variable depending on the echinoderm class. As a consequence, no clear patterns were detectable among the three study regions. Although regions may differ in their specific oceanographic properties, all regions are connected by the Gulf of Alaska and are influenced by its overall hydrographic characteristics. Some regional differences in diversity patterns may be driven by limits in biogeographical distribution of some species (Lambert, 1997, 2000), e.g., Prince William Sound being the reported northern distribution limit of Pisaster ochraceus (Lambert, 2000). If biogeographical limits were a significant contributor to regional variation in this study, we would expect this to be temporally consistent. Since patterns were inconsistent over years, we conclude that species distribution patterns only were a minor contributor to the observed horizontal regional variability.

Differences in echinoderm assemblages also were detected at the local horizontal scale despite choosing sites with similar substrate, exposure, and slope. The differences detected among sites within each region showed some temporal inconsistencies and disparities among echinoderm classes. This large variation at small local scales has been noted in other studies (Benedetti-Cecchi, 2001; Edwards, 2004). Much of this variation is probably caused by the inherent patchiness found in marine systems (Connell, 1972; Duggins, 1983; Pickett and White, 1985). In particular, mobile predators/scavengers such as asteroids are often patchily distributed and can cause a patchy distribution in the associated community due to their feeding patterns (Duggins, 1983; Brewer and Konar, 2005). Other benthic groups aggregate due to pulsed recruitment or gregarious behaviors (Connell, 1972; Burke, 1986; Raimondi, 1990; Konar, 2000). These mechanisms may explain the highly aggregated and patchily distributed abundance of some echinoderms, like Leptasterias hexactis, Pycnopodia helianthoides, Cucumaria vegae, Amphipholis spp., and Strongylocentrotus droebachiensis (e.g. Duggins, 1983; Arndt and Smith, 1998; Brewer and Konar, 2005).

Differences on local horizontal scales also occurred among echinoderm classes at each site and tidal height as well as between years. Some taxa, such as Leptasterias spp. Ophiopholis aculeata, Cucumaria vegae, and Strongylocentrotus droebachiensis, were found in many samples in all regions. In contrast, some groups occurred with only one or two individuals, including Pisaster ochraceus, Chiridota sp., Eupentacta quinquesemita, Leptosynapta sp., Parasticopus californicus, Pentamera sp., and Psolus squamatus. Overall, in our study, the similarity or dissimilarity between samples along horizontal and vertical spatial gradients was often driven by the presence of one or two individual species at particular sites. The identity of this 'driving factor', however, was not constant over time or space. 
Trends in echinoderm distribution patterns along the vertical emersion gradient seem more consistent and clear albeit different for individual echinoderm classes. This concept of zonation is widely accepted in marine ecology and the vertical gradient of immersion has long been recognized as a strong factor affecting littoral community structure (Stephenson and Stephenson, 1949; Connell, 1972; Paine, 1974; Lubchenco and Menge, 1978). Other studies also have identified vertical gradients as particularly strong factors in driving community composition when comparing vertical and horizontal variability (Benedetti-Cecchi, 2001; Davidson, 2005). In the northwest Mediterranean, small-scale spatial variability was similar along vertical and horizontal gradients, whereas at scales larger than the patch, horizontal variability in assemblages was greater than vertical gradient variability when using univariate analyses. Multivariate analyses showed significantly greater vertical than horizontal variation at small scales, with reversed trends at regional scales (Benedetti-Cecchi, 2001). In southwest Ireland, Davidson (2005) found that intertidal communities were primarily affected by the vertical gradient of immersion. This pattern is not unexpected as certain species and groups are either primarily intertidal or subtidal depending on physiological constraints and competitive abilities. Some echinoderm species are more abundant in the intertidal than subtidal (e.g. Leptasterias hexactis) whereas others are more cosmopolitan in their bathymetric distribution (e.g. Pycnopodia helianthoides; see Lambert, 2000 for references).

Overall, this study found asteroids (Leptasterias spp. being the most dominant asteroid encountered) and holothuroids (Cucumaria vegae being the most dominant holothuroid encountered) primarily in the intertidal and shallow subtidal zone, whereas ophiuroids (predominantly Amphipholis spp. and Ophiopholis aculeata) were primarily found in deeper waters. Echinoids did not show a strong vertical zonation pattern. Interestingly, within individual echinoderm classes, not all taxa behaved similarly. For example, while most asteroids were only observed in the intertidal zone, Evasterias troschelii, and Pycnopodia helianthoides were observed at most intertidal and subtidal heights. Some of these vertical distribution patterns may be explained by the reproduction, recruitment, or feeding strategies of individual taxa. A brooding species like Leptasterias hexactis may be particularly well adapted to an intertidal lifestyle, as it does not produce larvae that depend on tidal immersion for release and dispersal. Reproductive strategies may even vary among species within the same genus. For example, Cucumaria miniata has a lecithotrophic larval stage, whereas Cucumaria pseudocurata mostly inhabits the intertidal zone and broods its young (Arndt and Smith, 1998). Such life history differences can dramatically influence, and help explain, the distribution of each individual echinoderm species along vertical as well as horizontal gradients.

While our discussions above provide several explanations for some of the observed variability at various temporal and spatial scales, the scale of the sampling design may also influence variability. The hierarchically nested sampling design used in this study is appropriate to detect variability on various spatial scales. However, actual area of $625 \mathrm{~cm}^{2}$ per sample may be too small to appropriately sample some of the larger echinoderms, which may be distributed at a larger scale than this sample size can capture. We are unsure how much this may have contributed to the observed variability at the various temporal and spatial scales but we suggest that future studies employ variable sample sizes to analyze this factor.

In summary, this study emphasizes the high temporal and local-to-regional spatial variability in echinoderm populations in nearshore Alaska. The individual patterns observed cannot be generalized over time, over all regions, sites and tidal heights, or for all echinoderm groups. The factors 'Site' and 'Height*Site' often contributed to the most variability in our study and seemed to be the primary structuring forces in echinoderm distribution. Vertical (zonation) patterns seemed more consistent across these same temporal and spatial scales and were specific to different echinoderm groups. We suggest that this is in part due to a generally high adaptation to either an intertidal or subtidal lifestyle 
in various taxa, which may promote resilience towards factors that can otherwise significantly influence nearshore echinoderm distribution patterns. The drivers of temporal and horizontal spatial distribution are largely unknown, and are likely a combination of system-inherent patchiness, smallscale physical and biological events, and larger oceanographic factors. Interestingly, while these factors are strong enough drivers to cause significant differences in temporal and horizontal spatial scales, they do not obscure the underlying vertical zonation pattern within an intertidal and shallow subtidal system. Natural variability is particularly high in rocky shores, but the use of a 'one-size fits all' sampling unit may also contribute to the high 'noise-to-signal' ratio and our inability to detect consistent patterns.

\section{Acknowledgments}

We are greatly indebted to the Census of Marine Life and the Sloan Foundation for their vision of a global marine biodiversity program. We appreciate the generous support of the Gulf Ecosystem Monitoring Program for funding this study. Neil Oppen, Mike Geagel and David Kubiak have provided excellent logistical support in the field, and numerous students and volunteers have contributed to the sampling efforts. HC is grateful to the NaGISA program for sponsoring her participation at the echinoderm Taxonomy Workshop, which enabled taxonomic identification of the material, and her participation in the NaGISA World Congress. We also greatly appreciate the valuable comments from anonymous reviewers that contributed to improvements on the manuscript.

\section{References}

Aarset, A.V. 1982. Freezing tolerance in intertidal invertebrates (a review). Comparative Biochemistry and Physiology A, 73, 571-580.

Ambrose, W.G., Clough, L.M., Tilney, P.R. and Beer, L. 2001. Role of echinoderms in benthic remineralization in the Chukchi Sea. Marine Biology, 139, 937-949.

Arndt, A. and Smith, M.J. 1998. Genetic diversity and population structure in two species of sea cucumber: differing patterns according to mode of development. Molecular Ecology, 7, 1053-1064.

Balata, D., Acunto, S. and Franceso, C. 2006. Spatio-temporal variability and vertical distribution of a low rocky subtidal assemblage in the north-west Mediterranean. Estuarine, Coastal and Shelf Science, 67, 553-561.

Benedetti-Cecchi, L. 2001. Variability in abundance of algae and invertebrates at different spatial scales on rocky sea shores. Marine Ecology Progress Series, 215, 72-92.

Billett, D.S.M. 1991. Deep-see holothurians. Oceanography and Marine Biology, 29, 259-317.

Billett, D.S.M., Bett, B.J., Rice, A.L., Thurston, M.H., Galeron, J., Sibuet, M. and Wolff, G.A. 2001. Long-term change in the megabenthos of the Porcupine Abyssal Plain (NE Atlantic). Progress in Oceanography, 50, 325-348.

Brewer, R. and Konar, B. 2005. Chemosensory responses and foraging behavior of the seastar Pycnopodia helianthoides. Marine Biology, 147, 789-795.

Burke, R.D. 1986. Pheromones and the gregarious settlement of marine invertebrate larvae. Bulletin of Marine Science, 39, 323-331.

Carroll, M.L. and Highsmith, R.C. 1996. Role of catastrophic disturbance in mediating Nucella-Mytilus interactions in the Alaskan rocky intertidal. Marine Ecology Progress Series, 138, 125-133.

Chapman, M.G. 2002. Patterns of spatial and temporal variation of macrofauna under boulders in a sheltered boulder field. Australian Ecology, 27, 211-228.

Chapman, M.G. 2005. Molluscs and echinoderms under boulders: tests of generality of patterns of occurrence. Journal of Experimental Marine Biology and Ecology, 325, 65-83.

Connell, J.H. 1972. Community interactions on marine rocky intertidal shores. Annual Review of Ecology and Systematics, 3, 169-192.

Connolly, S.R. and Roughgarden, J. 1999. Increased recruitment of Northeast Pacific barnacles during the $1997 \mathrm{El}$ Niño. Limnology and Oceanography, 44, 466-469.

Davenport, J. and MacAlister, H. 1996. Environmental conditions and physiological tolerances of intertidal fauna in relation to shore zonation at Husvik, South Georgia. Journal of the Marine Biological Association of the United Kingdom, 76, 985-1002. 
Davidson, I.C. 2005. Structural gradients in an intertidal hard-bottom community: examining vertical, horizontal, and taxonomic clines in zoobenthic biodiversity. Marine Biology, 146, 827-839.

Dayton, P.K. and Tegner, M.J. 1984. The importance of scale in community ecology: a kelp forest example with terrestrial analogs. In, Price, P.W., Slobodchikoff, C.N., and Gaud, W.S. (eds). A New Ecology: Novel approaches to Interactive Systems, John Wiley \& Sons, New York, pp. 457-481.

Dayton, P.K., Tegner, M.J., Edwards, P.B. and Riser, K.L. 1998. Sliding baselines, ghosts, and reduced expectations in kelp forest communities. Ecological Applications, 8, 309-322.

Duggins, D.O. 1980. Kelp beds and sea otters: an experimental approach. Ecology, 61, 447-453.

Duggins, D.O. 1983. Starfish predation and the creation of mosaic patterns in a kelp-dominated community. Ecology, 64, 1610-1619.

Estes, J.A., Tinker, M.T., Williams, T.M. and Doak, D.F. 1998. Killer whale predation on sea otters linking oceanic and nearshore ecosystems. Science, 282, 473-476.

Edwards, M.S. 2004. Estimating scale-dependency in disturbance impacts: El Niños and giant kelp forests in the northeast Pacific. Oecologia, 138, 436-447.

Edwards, M.S. 2005. Delayed recovery of giant kelp near its southern range limit in the North Pacific following El Niño. Marine Biology, 147, 273-279.

Ellingsen, K.E. and Gray, J.S. 2002. Spatial patterns of benthic diversity: is there a latitudinal gradient along the Norwegian continental shelf? Journal of Animal Ecology, 71, 373-389.

Feder, H.M., Jewett, S.C. and Blanchard, A. 2005. Southeastern Chukchi Sea (Alaska) epibenthos. Polar Biology, 28, 402-421.

Gonzales-Medina, F.J., Holguin-Quiones, O.E., De la Cruz-Aguero, G. 2006. Spatiotemporal variability of some shallow-water macroinvertebrates (Gastropods, Bivalvia and Echinodermata) from Espiritu Santo Archipelago, Baja California Sur, Mexico. Ciencias Marinas, 32, 33-44.

Graham, M.H. and Edwards, M.S. 2001. Statistical significance vs. fit: estimating the importance of individual factors in ecological analysis of variance. Oikos, 93, 503-513.

Gutt, J. and Starmans, A. 2003. Patchiness of the megabenthos at small scales: ecological conclusions by examples from polar shelves. Polar Biology, 26, 276-278.

Hastings, A., Hom, C.L., Ellner, S., Turchin, P. and Godfray, H.C.J. 1993. Chaos in ecology: Is Mother Nature a strange attractor? Annual Review of Ecology and Systematics, 24, 1-33.

Hinz, H., Kroencke, I. and Ehrich, S. 2004. Seasonal and annual variability in an epifaunal community in the German Bight. Marine Biology, 144, 735-745.

Howell, K.L., Billett, D.S.M. and Tyler, P.A. 2002. Depth-related distribution and abundance of seastars (Echinodermata: Asteroidea) in the Porcupine Seabight and Porcupine Abyssal Plain, N.E. Atlantic. DeepSea Research (Part I, Oceanographic Research Papers), 49, 1901-1920.

Hughes, T.P., Baird, A.H., Moltschaniwskyj, N.A., Pratchett, M.S., Tanner, J.E., and Willis, B.L. 1999. Patterns of recruitment and abundance of corals along the Great Barrier reef. Nature, 397, 59-63.

Hunt, H.L. and Scheibling, R.E. 2001. Patch dynamics of mussels on rocky shores: integrating process to understand pattern. Ecology, 82, 3213-3231.

Konar, B. 2000. Seasonal inhibitory affects of marine plants on sea urchins: structuring communities the algal way. Oecologia, 125, 208-217.

Konar, B. and Estes, J. A. 2003. The stability of boundary regions between kelp beds and deforested areas. Ecology, 84, 174-185.

Lambert, P. 1997. Sea Cucumbers of British Columbia, Southeast Alaska and Puget Sound. UBC Press, Vancouver, $166 \mathrm{pp}$.

Lambert, P. 2000. Sea Stars of British Columbia, Southeast Alaska and Puget Sound. UBC Press, Vancouver, Toronto, $186 \mathrm{pp}$.

Levin, S.A. 1992. The problem of pattern and scale in ecology. Ecology, 73, 1943-1967.

Levin, S.A. 2000. Multiple scales and the maintenance of biodiversity. Ecosystems, 3, 498-506.

Mann, K.H. and Breen, P.A. 1972. The relation between lobster abundance, sea urchins, and kelp beds. Journal of Fisheries Research Board of Canada, 29, 603-609.

McNaughton, S.J. 1977. Diversity and stability of ecological communities: a comment on the role of empiricism in ecology. The American naturalist, 111, 515-525.

Menconi, M., Benedetti-Cecchi, L. and Cinelli, F. 1999. Spatial and temporal variability in the distribution of 
algae and invertebrates on rocky shores in the northwest Mediterranean. Journal of Experimental Marine Biology and Ecology, 233, 1-23.

Menge, B.A., Berlow, E.L., Blanchette, C.A., Navarrete, S.A. and Yamada, S.B. 1994. The keystone species concept: variation in interaction strength in a rocky intertidal habitat. Ecological Monographs, 64, 249-286.

Migne, A. and Davoult, D. 1997. Quantitative distribution of benthic macrofauna of the Dover Strait pebble community (eastern English Channel, France). Oceanologica Acta, 20, 453-460.

Nakashizuka, T. and Stork, N. 2002. Biodiversity Research Methods: IBYO in Western Pacific and Asia. Kyoto University Press, 216 pp.

Noda, T. 1999. Within- and between-patch variability of predation intensity on the mussel Mytilus trossolus Gould on a rocky intertidal shore in Oregon, USA. Ecological Research, 14, 193-203.

Paine, R.T. 1966. Food web complexity and species diversity. The American Naturalist, 100, 65-75.

Paine, R.T. 1974. Intertidal community structure. Oecologia, 15, 93-120.

Paine, R.T. and Trimble, A.C. 2004. Abrupt community change on a rocky shore - biological mechanisms contributing to the potential formation of an alternative state. Ecology Letters, 7, 441-445.

Pickett, S.T.A. and White, P.S. 1985. The ecology of natural disturbance and patch dynamics. Academic Press, Orlando, Florida, USA, 472 pp.

Piepenburg, D. 2000. Arctic brittle stars (Echinodermata: Ophiuroidea). Oceanography and Marine Biology: An Annual Review, 38, 189-256.

Piepenburg, D., Voß, J. and Gutt, J. 1997. Assemblages of se stars (Echinodermata: Asteroidea) and brittle stars (Echinodermata: Ophiuroidea) in the Weddell Sea (Antarctica) and off Northeast Greenland (Arctic): a comparison of diversity and abundance. Polar Biology, 17, 305-322.

Raimondi, P.T. 1990. Patterns, mechanisms, consequences of variability in settlement and recruitment of an intertidal barnacle. Ecological Monographs, 60, 283-309.

Rigby, P.R., Kato, T. and Riosmena-Rodriguez, R. 2007. NaGISA rocky shore protocol. In, Rigby, P.R., Iken, K. and Shirayama Y. (eds). Sampling Biodiversity in Coastal Communities: NaGISA Protocols for Seagrass and Macroalgal Habitats. Kyoto University Press, Japan, pp. 17-21.

Rumrill, S.S. 1988. Temporal and spatial variability in the intensity of recruitment of a sea star: frequent recruitment and demise. American Zoologist, 28, 123A.

Smith, J.R., Fong, P., Ambrose, R.F. 2006. Dramatic declines in mussel bed community diversity: Response to climate change? Ecology, 87, 1153-1161.

Stephenson, T.A. and Stephenson, A. 1949. The universal feature of zonation between tide-marks on rocky coasts. Journal of Ecology, 37, 289-305.

Tegner, M.J. and Dayton, P.K. 1991. Sea urchins, El Niños, and the long term stability of Southern California kelp forest communities. Marine Ecology Progress Series, 77, 49-63.

Underwood, A.J. 1997. Experiments in Ecology. Cambridge University Press, Cambridge 504 pp.

Vadas, R.L., Elner, R.W., Garwood, P.E. and Babb, I.G. 1986. Experimental evaluation of aggregation behaviour in the sea urchin Strongylocentrotus droebachiensis. A reinterpretation. Marine Biology, 90, 433-448.

Weins, J.A. 1989. Spatial scaling in ecology. Functional Ecology, 3, 385-397. 